\title{
Plasma catalase, glutathione-s-transferase and total antioxidant activity levels of children with attention deficit and hyperactivity disorder
}

\author{
V. Kenan Çelik ${ }^{*}$, Erdal Erşan ${ }^{2}$, Serpil Erşan $^{3}$, Sevtap Bakır $^{1}$, Orhan Dogan $^{4}$ \\ ${ }^{1}$ Departments of Biochemistry, School of Medicine, Cumhuriyet University, Sivas, Turkey \\ ${ }^{2}$ Numune Hospital, Sivas, Turkey \\ ${ }^{3}$ Department of Chemistry Engineering, School of Medicine, Cumhuriyet University, Sivas, Turkey \\ ${ }^{4}$ Departments of Clinical Psychiatry, School of Medicine, Cumhuriyet University, Sivas, Turkey \\ Email: ${ }^{*}$ kenanim123@yahoo.com, ${ }^{*}$ vkcelik@cumhuriyet.edu.tr
}

Received 14 September 2012; revised 16 October 2012; accepted 24 October 2012

\begin{abstract}
Objective: In this study, we plan to measure plasma Catalase (CAT), Antioxidant Activity (AOA) and Glutathione-S-Transferase (GST) levels to understand whether oxidative stress develops or not and whether or not the detoxification mechanism properly functions in children with Attention Deficit and Hyperactivity Disorder (ADHD) with unknown etiology and pathogenesis. Method and Results: Plasma CAT, AOA, and GST activities were spectrophotometrically measured in forty patients (average age 10.27 \pm 2.54 ) and thirty-five (average age, $9.97 \pm 2.59$ ) healthy individuals as the control group. While the CAT activity showed no difference in the patient group $(P>0.05)$ compared to the control group, AOA and GST levels were found significantly meaningful $(P=0.001)$. Conclusion: In this pilot study, the study shows that no oxidative stress develops in individuals with ADHD in high AOA and stable CAT activity, and that the detoxification mechanism functions extremely in high GST activity. These findings need to be supported by other studies.
\end{abstract}

Keywords: ADHD; Catalase; Antioxidant Activity; Oxidative Stress; Glutathione-S-Transferase

\section{INTRODUCTION}

Oxidative stress is generally considered as a condition underlying many diseases, and it is defined as an increase in reactive oxygen species (ROS) or a decrease in antioxidant defense. ROS are molecules containing hydrogen peroxide $\left(\mathrm{H}_{2} \mathrm{O}_{2}\right)$ formed during normal metabolism processes, superoxide $\left(\mathrm{O}_{2}^{-}\right)$and particularly an unstable oxygen atom like the hydroxyl radical $(\mathrm{OH})$,

\footnotetext{
${ }^{*}$ Corresponding author.
}

which is harmful for all tissues. The capacity of antioxidant defense systems to catch ROS is highly important in protecting the tissues from oxidative damage. Cells and biological fluids have a series of enzymatic (like Superoxide dismutase (SOD), Catalase (CAT), Glutathione peroxidase (GPX), Glutathione-S-Transferase (GST)) and non-enzymatic (Tocopherols, Carotenoids, and Flavonoids as lipid phase; Ascorbate, Urate, Glutathione, and other thiols as liquid phase) protective antioxidant mechanisms; acting together, they protect the cells from oxidative damage and prevent the formation of radicals [1-4]. The total antioxidative serum capacity is not a simple sum of the various antioxidative substances. It is a dynamic equilibrium that is influenced by the interactions such as cholesterol, urea, proteins etc. between each serum antioxidative constituent.

Attention Deficit and Hyperactivity Disorder, characterized by semptomps of inattention, hyperactivity and impulsivity, is a very common psychological disorder that affects $5 \%-10 \%$ [5-7] of elementary school children aged between $5-12$ years [8]. These children were characterized by ADHD even in older ages, also bearing behaviors like attention deficit, hyperactivity and impulsivity [9]. Although different treatments and therapies were practiced in the treatment of ADHD, no satisfactory results could be achieved [10]. Although studies conducted and evidences found suggest that the disorder can most probably be associated with genetic factors [11,12], it appears as a complex structure also covering environmental factors such as lead poisoning, nutrient sensitivity or nutritional anomaly $[13,14]$. This is why the major underlying cause of the disease remains mysterious.

There are few and conflicting studies about oxidative stress in patients with ADHD. While some of these studies suggest that oxidative stress may develop because saturated fatty acid (SFA) levels are higher than $\omega-3$ levels of poly-unsaturated fatty acids (PUFAs) that are nec- 
essary particularly for brain functioning and development [15-18], another study report no changes in oxidative stress and antioxidant vitamin levels including $\omega-3$ fatty acids [19]. Obviously, many more studies are needed in order to clarify the findings in this area.

Catalase (CAT, EC: 1.11.1.6) is a glycoprotein present in the antioxidant defense system of all cells and organelles and transforming $\mathrm{H}_{2} \mathrm{O}_{2}$ to $\mathrm{H}_{2} \mathrm{O}$ and $\mathrm{O}_{2}$ [20]. Glutathione-S-Transferase (GST, EC: 2.5.1.18) is a dimeric protein with a multifunctional family (belonging to three different gene families named as Alpha, $\mathrm{Mu}$, and $\mathrm{Pi}$ ) playing a major role in detoxifying enzymes. Mainly, it protects cells from toxins via biotransformation reactions in the cytoplasm. And it carries out this function by conjugating harmful endogenous or exogenous chemicals with glutathione (GSH) [21,22].

In this pilot study, we aim to measure plasma Antioxidant activity (AOA), Catalase and Glutathione-STransferase (GST, EC: 2.5.1.18) activities of patients and controls with ADHD.

\section{MATERIAL AND METHOD}

\subsection{Constitution of Study Groups}

Forty children (mean age $10.27 \pm 2.54$ ) were included in the study, who were taken by their parents to the Outpatient's Clinic of Psychiatry of Sivas Numune Hospital and diagnosed with ADHD for the first time. The diagnosis of ADHD was principally established according to medical history and DSM-IV criteria [23]; parents of children in the study group were asked to fill out the "Screening and Evaluation Scale of Destructive Behavioral Disorders" based on DSM-IV and this data was combined with clinical examination to establish a diagnosis of (ADHD) in children meeting the DSM-IV criteria. Concomitantly, newly diagnosed children with no extensive developmental disorders, schizophrenia, epilepsy or other medical conditions and no history of psychopharmacological therapies were included in the study. Children with epilepsy, psychosis, mental retardation, autism and major brain abnormality were excluded from the study. Other tests (Childhood Depression Scale, Learning Deficits Screening Scale) were administered to exclude other disorders presenting with symptoms of ADHD and children testing positive in these were excluded from the study. Control group consisted of 35 (mean age $9.97 \pm 2.59$ ) healthy children, exactly matching the ADHD group in terms of age and sex, selected from schools for a previously performed study via simple random sampling method.

None of the cases received medical treatment. There were no co-morbid conditions in our study. Children and their parents in both groups were informed of the study in a detailed manner and consent forms were signed.

\subsection{Collection of Blood Samples}

Venous blood samples were taken into tubes containing ethylenediamine tetraacetic acid (EDTA) between 9.00 10.00 in the morning after 8 hours of fasting and were placed immediately into a $4^{\circ} \mathrm{C}$ ice bath. They were then centrifuged for 10 minutes at $3000 \mathrm{rpm}$ to separate the plasma and kept at $-80^{\circ} \mathrm{C}$ until an analysis is made, divided into Eppendorf tubes in various quantities.

\subsection{Catalase, Glutathione-S-Transferase, and Total Antioxidant Measurements}

Catalase activity was made by spectrophotometric measurement of decreasing $\mathrm{H}_{2} \mathrm{O}_{2}$ quantity at a wavelength of $240 \mathrm{~nm}$, defined by Beers and Sizer [24]. One unit of activity was defined as an enzyme activity $(\mathrm{U} / \mathrm{ml})$ degrading one micromole of $\mathrm{H}_{2} \mathrm{O}_{2}$ in one minute under standard conditions. GST activity was spectrophotometrically measured at a wavelength of $340 \mathrm{~nm}$ according to the method defined by Habig et al. [25]. Under standard conditions, the amount of enzyme conjugating one micromole of 1-chloro-2,4-dinitrobenzene (CDNB) with Glutathione (GSH) in one minute was defined as one unit activity (mmol/L). Antioxidant activity was spectrophotometrically identified at $532 \mathrm{~nm}$ according to the method defined by Koraceviv et al. [26]. Total antioxidant activity was given as $\mathrm{mmol} / \mathrm{L}$.

\subsection{Chemicals}

All chemicals were analytically pure and supplied by Sigma Chemical Company (St. Louis, USA).

\subsection{Statistical Analysis}

Parametric data are expressed as the mean \pm standard deviation and categorical data as percentages. The Statistical Package for the Social Sciences (SPSS) version 14 for Windows (SPSS Inc., Chicago, IL, USA) was used for the statistical analysis. Parametric data were evaluated by the independent sample t-test and categorical data by the chi-squared test. A P value $\leq 0.05$ was considered as significant.

\section{RESULTS}

Fourty patients with ADHD and 35 control subjects were recruited for the study. Of the ADHD patients, 25 (63\%) were male and $15(37 \%)$ female, and the mean age was $10.27 \pm 2.54$ years. In the control group, $24(69 \%)$ individuals were male and $11(31 \%)$ were female, with a mean age of $9.97 \pm 2.59$ years. There were no significant differences in the age or sex ratio between patients with ADHD and controls $(\mathrm{P}>0.05)$ (Table 1). Plasma CAT activity of the patient group was found $65.77 \pm 28.2$ 
Table 1. Mean age, gender, plasma CAT, GST and AOA levels of ADHD and controls.

\begin{tabular}{cccc}
\hline & Patients & Controls & \\
\hline & $(\mathrm{n}=40)$ & $(\mathrm{n}=35)$ & $\mathrm{P}$ \\
Mean age, (year) & $10.27 \pm 2.54$ & $9.97 \pm 2.59$ & 0.611 \\
Gender, girl/boy & $15 / 25$ & $11 / 24$ & 0.58 \\
Catalase $(\mathrm{U} / \mathrm{ml})$ & $65.77 \pm 28.2$ & $71.43 \pm 17.7$ & 0.325 \\
GST $(\mu \mathrm{mol} / \mathrm{L})$ & $5.31 \pm 1.71$ & $3.36 \pm 1.4$ & 0.001 \\
AOA $(\mathrm{mmol} / \mathrm{L})$ & $0.8599 \pm 0.0355$ & $0.3143 \pm 0.0791$ & 0.001
\end{tabular}

Data expressed as mean \pm standard deviation.

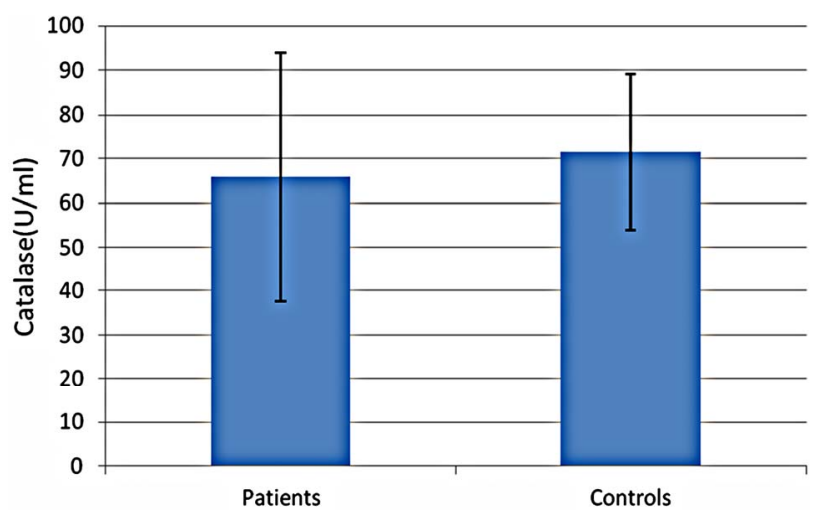

Figure 1. Catalase activity in both groups.

$\mathrm{U} / \mathrm{ml}$, and $71.43 \pm 17.7 \mathrm{U} / \mathrm{ml}$ in the control group. No statistical differences were found between the groups $(\mathrm{P}$ $=0.091)$ (Figure 1). GST activity was found significantly higher $(\mathrm{P}=0.001)$ in the patient group $(5.31 \pm$ $1.71 \mathrm{U} / \mathrm{ml})$ compared to the control group $(3.36 \pm 1.4)$ (Figure 2). And AOA activities were also found significantly higher $(\mathrm{P}=0.001)$ in $\mathrm{ADHD}(0.8599 \pm 0.0355$ $\mathrm{mmol} / \mathrm{L})$ compared to the control group $(0.3143 \pm$ $0.0791 \mathrm{mmol} / \mathrm{L})$ (Figure 3). All results are shown in Table 1.

\section{DISCUSSION}

Clinically relevant antioxidants are classified into two groups: preventive and chain breaking antioxidants $[27,28]$. Preventive antioxidants prevent the initiation of radical chain reactions by reducing hydroperoxides to molecular species without the formation of free radicals, or by sequestering transition metals (iron, copper), thereby preventing them from participating in reactive radical production. Chain breaking antioxidants can trap free radicals directly, thereby interrupting chain propagating reactions. The known preventive antioxidants of biological systems are: catalase, glutathione peroxidase and metal binding proteins (treansferrin, ceruloplasmin, and albumin); chain breaking antioxidants are: SOD, uric

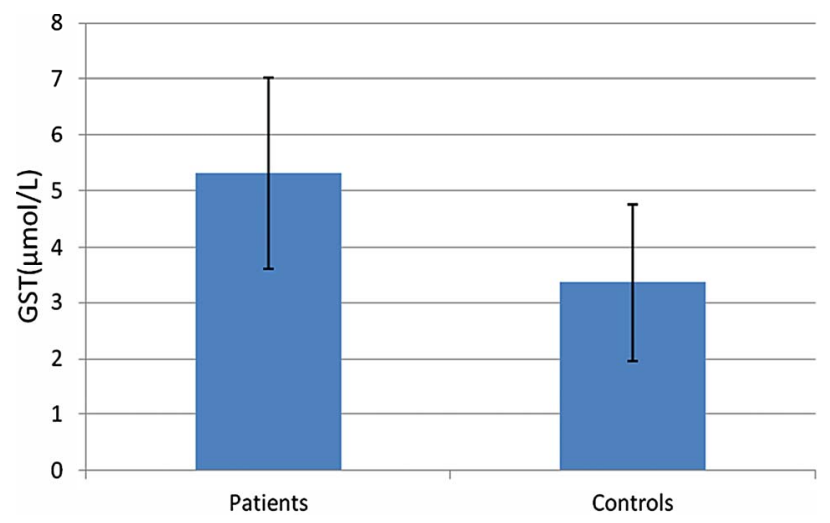

Figure 2. GST activity in both groups.

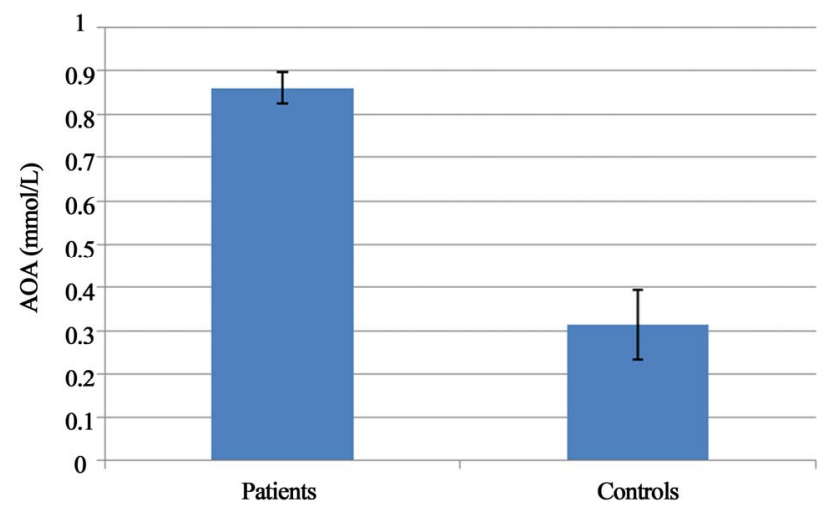

Figure 3. AOA in both groups.

acid, protein sulphhydryls, ascorbate, $\alpha$-tocopherol, glutathione and bilirubin. Human plasma has a chain breaking antioxidant capacity that allows it to trap free radicals (approximately $0.70-1.00 \mathrm{mmol} /$ litre) [27]. Although the presented study shows no statistically meaningful difference in CAT activity in both groups, GST and AOA activities were found significantly higher $(P=0.01)$ in the patient group as demonstrated in Table 1. Stable CAT activity (Figure 1) shows that $\mathrm{H}_{2} \mathrm{O}_{2}$ formed during normal processes of the metabolism was seamlessly transformed into $\mathrm{H}_{2} \mathrm{O}$ and $\mathrm{O}_{2}$. Besides, high AOA shows that the metabolism creates a higher protection potential against oxidative damage. Although it was argued that there is an improvement in the behaviors of children with ADHD who are administered an antioxidant like Pycnogenol (a substance accelerating blood flow, and containing anthocyanidin and polyphenol) [29] extracted from flaxseed oil and ananas peel, rich in alpha linoleic acid and containing vitamin $\mathrm{C}$ [30] as antioxidant, and although it was argued that they protect from oxidative damage, our findings (Figure 3) support Spahis et al.'s results, suggesting that children with ADHD were not subjected to oxidative stress [19]. High GST activity found in patients in our study group also shows that the detoxification mechanism works excessively (Figure 2). A more comprehensive study should be made to investi- 
gate whether or not the cause underlying this increase in GST activity is a substance chronically exposed to or a metabolite, also looking into the genetic polymorphism of this enzyme.

\section{CONCLUSION}

The results we obtained in our study suggest that no oxidative damage develops in children with ADHD, and no oxidative stress is caused. Further studies are needed to clarify the details on the subject matter discussed here.

\section{REFERENCES}

[1] Young, I.S. and Woodside, J.V. (2001) Antioxidants in health and disease. Journal of Clinical Pathology, 54, 176186. doi: $10.1136 /$ jep.54.3.176

[2] Change, B., Sies, H. and Baveris, A. (1979) Hydroperoxide metabolism in mammalian organs. Physiological Reviews, 59, 527-605.

[3] Yu, B.P. (1994) Cellular defenses from damage from reactive oxygen species. Physiological Reviews, 74, 139-162.

[4] Reiter, R.J. (1995) Oxidative processes and antioxidative defense mechanism. FASEB Journal, 9, 526-533.

[5] Faraone, S.V., Sergeant, J., Gillberg, C. and Biederman, J. (2003) The worldwide prevalence of ADHD: Is it an American condition? World Psychiatry, 2, 104-113.

[6] Biederman, J. and Faraone, S.V. (2005) Attention-deficit hyperactivity disorder. Lancet, 366, 237-248. doi:10.1016/S0140-6736(05)66915-2

[7] Wolraich, M.L., Wibbelsman, C.J., Brown, T.E., Evans, S.W., Gotlieb, E.M., Knight, J.R., et al. (2005) Attentiondeficit/hyperactivity disorder among adolescents: A review of the diagnosis, treatment, and clinical implications. $\mathrm{Pe}$ diatrics, 115, 1734-1746. doi:10.1542/peds.2004-1959

[8] American Psychiatric Association (2005) Diagnostic and statistical manual of mental disorders. American Psychiatric Association, Washington DC.

[9] Biederman, J., Petty, C.R., Evans, M., Small, J. and Faraone, S.V. (2010) How persistent is ADHD? A controlled 10-year follow-up study of boys with ADHD. Psychiatry Research, 177, 299-304. doi:10.1016/j.psychres.2009.12.010

[10] Conners, C.K., Epstein, J.N., March, J.S., Angold, A., Wells, K.C., Klaric, J., et al. (2001) Multimodal treatment of ADHD in the MTA: An alternative outcome analysis, Journal of the American Academy of Child \& Adolescent Psychiatry, 40, 159-167. doi:10.1097/00004583-200102000-00010

[11] Faraone, S.V., Perlis, R.H., Doyle, A.E., Smoller, J.W., Goralnick, J.J., Holmgren, M.A., et al. (2005) Molecular genetics of attention-deficit/hyperactivity disorder. Biological Psychiatry, 57, 1313-1323. doi:10.1016/j.biopsych.2004.11.024

[12] Khan, S.A. and Faraone, S.V. (2006) The genetics of attention-deficit/hyperactivity disorder: A literature review of 2005. Current Psychiatry Reports, 8, 393-397.

\section{doi:10.1007/s11920-006-0042-y}

[13] Kaplan, B.J., McNicol, J., Conte, R.A. and Moghadam, H.K. (1989) Dietary replacement in preschool-aged hyperactive boys. Pediatrics, 83, 7-17.

[14] Carter, C.M., Urbanowicz, M., Hemsley, R., Mantilla, L., Strobel, S., Graham, P.J., et al. (1993) Effects of a few food diet in attention deficit disorder. Archives of Disease in Childhood, 69, 564-568. doi:10.1136/adc.69.5.564

[15] Ross, M.A. (2000) Could oxidative stress be a factor in neurodevelopmental disorders? Prostaglandins, Leukotrienes and Essential Fatty Acids, 63, 61-63. doi:10.1054/plef.2000.0192

[16] Chen, J.R., Hsu, S.F., Hsu, C.D., Hwang, L.H. and Yanget, S.C. (2004) Dietary patterns and blood fatty acid composition in children with attention-deficit hyperactivity disorder in Taiwan. Journal of Nutritional Biochemistry, 15, 467-472. doi:10.1016/i.jnutbio.2004.01.008

[17] Young, G.S., Maharaj, N.J. and Conquer, J.A. (2004) Blood phospholipid fatty acid analysis of adults with and without attention deficit/hyperactivity disorder. Lipids, 39, 117-123.

[18] Mitchell, E.A., Aman, M.G., Turbott, S.H. and Manku, M. (1987) Clinical characteristics and serum essential fatty acid levels in hyperactive children. Clinical Pediatrics (Phila), 26, 406-411. doi:10.1177/000992288702600805

[19] Spahis, S., Vanasse, M., Bélanger, S.A., Ghadirian, P., Grenier, E. and Levy, E. (2008) Lipid profile, fatty acid composition and pro- and anti-oxidant status in pediatric patients with attention-deficit/hyperactivity disorder. Prostaglandins, Leukotrienes and Essential Fatty Acids, 79, 47-53. doi:10.1016/j.plefa.2008.07.005

[20] Masters, C., Pegg, M. and Crane, D. (1986) On the multiplicity of the enzyme in mammalian liver. Molecular and Cellular Biochemistry, 70, 113-120. doi:10.1007/BF00229426

[21] Khurana, S., Corbally, M.T., Manning, F., Armenise, T., Kierce, B. and Kilty, C. (2002) Glutathione S-transferase: A potential new marker of intestinal ischemia. Journal of Pediatric Surgery, 37, 1543-1548. doi:10.1053/jpsu.2002.36181

[22] Awasthi, Y.C., Sharma, R. and Singhal, S.S. (1994) Human glutathione S-transferase. International Journal of Biochemistry, 26, 295-308. doi:10.1016/0020-711X(94)90050-7

[23] American Psychiatric Association (1994) Diagnostic and statistical manual of mental disorders DSM-IV. 4th Edition, APA Press, Washington DC.

[24] Beers Jr, R.F. and Sizer, I.W. (1952) A spectrophotometric method for measuring the breakdown of hydrogen peroxide by catalase. Journal of Biological Chemistry, 195, 133.

[25] Habig, W.H., Pabst, M.J. and Jacob, W.B. (1974) Glutathione S-transferase. The first enzymatic step in mercapturic acid formation. Journal of Biological Chemistry, 249, 7130-7139.

[26] Koracevic, D., Koracevic, G., Djordjevic, V., Andrejevic, S. and Cosic, V. (2001) Method for the measurement of antioxidant activity in human fluids. Journal of Clinical 
Pathology, 54, 356-361. doi:10.1136/jcp.54.5.356

[27] Wayner, D.D.M., Burton, G.W., Ingold, K.U., Barclay, L.R.C. and Locke, S.J. (1987) The relative contributions of vitamin E, urate, ascorbate and proteins to the total peroxyl radical-trapping antioxidant activity of human blood plasma. Biochimica et Biophysica Acta, 924, 408419. doi:10.1016/0304-4165(87)90155-3

[28] Woodford, F.P. and Whitehead, T.P. (1998) Is measuring serum antioxidant capacity clinically useful? Annals of Clinical Biochemistry, 35, 48-56.

[29] Chovanova, Z., Muchova, J., Sivonova, M., Dvorakova,
M., Zittnanova, I., Waczulikova, I., et al. (2006) Effect of polyphenolic extract, pycnogenol, on the level of 8oxoguanine in children suffering from attention deficit/ hyperactivity disorder. Free Radical Research, 40, 10031010. doi:10.1080/10715760600824902

[30] Joshi, K., Lad, S., Kale, M., Patwardhan, B., Mahadik, S.P., Patni, B., et al. (2006) Supplementation with flax oil and vitamin $\mathrm{C}$ improves the outcome of Attention Deficit Hyperactivity Disorder (ADHD). Prostaglandins, Leukotrienes and Essential Fatty Acids, 74, 17-21. doi:10.1016/i.plefa.2005.10.001 